\title{
FLUOSILICATO DE ZINCO NA PREVENÇÃO DE CÃRIE DENTAL EM RATOS (1)
}

\begin{abstract}
O propósito desta pesquisa foi verificar uma possível ação sinérgica entre flúor e zinco na incidência da cárie dental. $O$ estudo compreendeu três grupos de ratos que receberam soluções de: a) fluoreto de sódio (1 ppm); b) fluosilicato de zinco; c) e água, respectivamente. Todos os grupos, com ratos machos e fêmeas, eram divididos em subgrupos de acôrdo com a dieta - cariogênica e não cariogênica. Os dados obtidos foram submetidos à análise de variância, concluíndo-se o seguinte: I) $O$ grupo que recebeu fluosilicato de zinco apresentou menor número de cáries do que o do fluoreto de sódio, mas a diferença não foi estatìsticamente significante, sendo, porém, significante entre êstes dois grupos e o da água. II) Os ratos que receberam o fluosilicato de zinco ou o fluoreto de sódio, mostraram nivel mais elevado de flúor nas cinzas dos ossos, mas a diferença entre os dois grupos não foi estatìsticamente significante. III) Notou-se também que apresentavam similar desmineralização óssea.
\end{abstract}

\section{N T R O DUÇAO}

A cárie dental é o principal problema da Odontologia Sanitária no Brasil. A situação mundial é comparável à brasileira, sendo mais fácil enumerar os países em que o problema da cárie não é o principal do que catalogar aquêles em que o é.

A focalização dêsse magno problema pode ser feita de dois pontos de vista principais: o preventivo e o curativo.

Dentro do espírito da Odontologia Preventiva, delineamos o presente trabalho segundo o primeiro dêsses ângulos, isto é, o da prevenção.

É bem reconhecida entre os autores contemporâneos a importância do flúor, quando ingerido com a água, para a proteção da integridade do esmalte dental. Boa estimativa dêsse consenso de opinióes pode ser encontrada entre os estudiosos do assunto: BLANEY ${ }^{5}$ (1960), Ast \& Fitzgerald ${ }^{3}$ (1962), Arnold et alii $^{2}$ (1962), Loures \& FreIre ${ }^{13}$ (1962) e Brown ${ }^{6}$ (1962), cujos trabalhos mostram a eficiência da fluoretação em Evanston, Newburgh e Gran Rapids nos EE.UU., Baixo Guandu no Brasil e Brantford no Canadá, respectivamente.

Noutra ordem de idéias, Hess \& LEE ${ }^{1 n}$ (1952), por exemplo, verificaram que o flúor é, dos elementos-traço, o de maior concentração no esmalte dental, seguindo-se imediatamente o zinco.

Brudevold, Steadman \& Smith $^{\text {7 }}$ (1960), ao analisarem os componentes orgânicos e inorgânicos dos dentes, relataram que o zinco é depositado primeiramente na porção inorgânica do esmalte e que a proporção em que é fixado é da mesma ordem da do flúor. Relataram, também, que a superfície do esmalte contém pelo menos duas a três vêzes mais zinco do que as camadas internas.

Recebido para publicação em 31-7-1967.

(1) Resumo da Tese de Doutoramento apresentada à Faculdade de Odontologia de Universidade de São Paulo.

(2) Da Cadeira de Odontologia Sanitária da Faculdade de Higiene e Saúde Pública da USP. 
VIEGAS, Ivette - Fluosilicato de zinco na prevenção de cárie dental em ratos. Rev. Saude puibl., 1(1):79-91, jun. 1967.

Com base nessas informações, pensamos na hipótese do flúor e do zinco poderem apresentar ação sinérgica capaz de resultar em maior resistência do dente à cárie.

Decidimos, assim, investigar o efeito preventivo do fluosilicato de zinco, por comparação com o do fluoreto de sódio.

\section{MATERIAL E METODOS}

Animais de experiência e materiais dêles obtidos - Utilizamos nas nossas experiências ratos albinos ((Rattus Norwegicus) da variedade McCollum. Tomamos, de início, seis lotes de fêmeas adultas que, desde o acasalamento, passaram a receber diferentes tratamentos, referidos na Tabela $l$.
Tanto a água de bebida nos lotes-testemunha (5 e 6), como as soluções de fluoreto de sódio e de fluosilicato de zinco, nos lotes tratados respectivamente (1 e 2, e 3 e 4), foram dadas ad libitum. As rações também o foram.

Dos descendentes, foram conservados 10 machos e 10 fêmeas por lote, sendo escolhidos os primeiros nascidos. Cada um dêles permaneceu na dieta do lote respectivo até o $1200^{\circ}$ dia de vida.

Os animais foram então sacrificados por inalação de éter, recebendo nova numeração, independente da primeira (double blind); de todos êles foram retirados: fígado, rim e tireóide, para exame histológico; fêmures, para dosagem de flúor; cabeças, para contagem de cárie dental.

T A B E L A 1

Tipos de tratamento a que cada lote fol submetido

\begin{tabular}{|c|c|c|c|c|c|}
\hline $\begin{array}{l}\text { Número } \\
\text { do lote }\end{array}$ & $\begin{array}{c}\text { Racão } \\
\text { A }\end{array}$ & $\begin{array}{c}\text { Ração } \\
\text { B }\end{array}$ & $\begin{array}{l}\text { Solucão aquosa a } \\
1 \text { ppm de fluo- } \\
\text { reto de sódío }\end{array}$ & $\begin{array}{l}\text { Solução aquosa a } \\
1 \text { ppm de fluo- } \\
\text { silicato de zinco }\end{array}$ & Agua \\
\hline 1 & + & & + & & \\
\hline 2 & & + & + & & \\
\hline 3 & + & & & + & \\
\hline 4 & & + & & + & \\
\hline 5 & + & & & & + \\
\hline 6 & & + & & & + \\
\hline
\end{tabular}

Convenção: o sinal + indica os componentes de cada tratamento.

Compostos de flúor - Os sais empregados foram o fluoreto de sódio e o fluosilicato de zinco, cujas soluções eram preparadas em duas fases: na primeira, preparava-se uma solução a 1:1000 em água destilada; na segunda fase tomava-se uma alíquota da primeira solução e diluia-se em água de torneira, de modo a que a concentração final fôsse a de 1 ppm.
Rações - A ração A era ração normal e a $B$, ração cariogênica, com $20 \%$ de sacarose.

Dosagem do flúor nos ossos dos ratos - A determinação foi feita a partir das cinzas dos fêmures dos animais. Depois de sacrificado, $\circ$ animal era submetido a uma autoclavagem a $120^{\circ} \mathrm{C}$ por $15 \mathrm{mi}$ nutos. Este tratamento facilitava 0 se- 
VIEGAS, Ivette - Fluosilicato de zínco na prevenção de cárie dental em ratos. Rev. Saúde públ., 1(1):79-91, Jun. 1967.

parar os ossos das partes moles externas. Dessecavam-se os fêmures que a seguir eram triturados em almofariz, o pó pesado em cadinhos de porcelana e reduzido a cinzas à temperatura de $550^{\circ} \mathrm{C}$.

Obtidas as cinzas, estas eram pesadas e submetidas à técnica preparatório de Singer \& Armstrong ${ }^{21}$ (1954) com a modificação do frasco de difusão, introduzida por TAMBURINI \& ZuCAS ${ }^{25}$ (1964). A seguir a determinação era feita pela técnica espectro-fotométrica de MEGREGIAN $^{17}$ (1954).

Técnicas histológicas - Dos animais, logo em seguida ao secrifício, retirávamos fígado, rim e glândula tireóide, fixando-os em líquido Bouin. Em seguida, as peças passavam pelo método rotineiro de inclusão em parafina, obtendo-se depois cortes de 5 micra pela técnica usual.

Os métodos de coloração empregados foram a hematoxilina-eosina e o tricrômico de Mallory.

A coloração foi feita apenas em animais sorteados, num total de 30 (aproximadamente $30 \%$ daqueles que constituiam o material).

Técnica de contagem de cárie - Após a autoclavagem a $120^{\circ} \mathrm{C}$, por 15 minutos, já referida, as cabeças eram livradas das partes moles externas para que se pudessem contar as cáries pela técnica devida a KEYs ${ }^{11}$ (1958).

Procedemos da seguinte maneira:

1) As cabeças eram imersas durante 24 horas em solução aquosa saturada de "Vermelho Nuclear" (Kernechtrot B salt). Em seguida eram lavadas e depois sêcas por jato de ar.

2) Os molares inferiores e superiores eram então hemiseccionados no sentido mesio-distal com disco de aço serrilhado, de 0,004 polegada de espessura por 0,75 polegada de diâmetro. 0 disco era montado em mandril na peça de mão de um motor de baixa rotação. Durante a operação, um jato de água era aplicado sô- bre os molares que estavam sendo cortados.

3) Passando à contagem pròpriamente dita, optamos por anotar o número de lesões de cárie, lesões estas encontradas através do exame da superfície de corte ao microscópio estereoscópico.

\section{METODOS ESTATISTICOS}

Análise de Variância - Foi feita para testar se havia diferenças relacionadas aos fatôres - Solução, Ração e Sexo. Como no fim da experiência alguns lotes estavam apenas com oito ratos decidimos excluir os excedentes dêsse número, o que foi feito por sorteio. Essa medida foi tomada a fim de que os dados pudessem ser submetidos a uma análise de variância a três critérios, com o mesmo número de observações nas sub-classes para cada fator a ser analisado.

Os testes de hipóteses foram feitos ao nível de $5 \%$.

Transformação $\sqrt{\mathrm{x}+\frac{1}{2}}-\mathrm{Na}$ análise dos dados referentes à cárie foi usada a transformação segundo a expressão $\sqrt{x+\frac{1}{2}}(x=$ percentagem de lesões de cárie por rato). Essa transformação foi feita a fim de permitir o emprềgo subseqüente da análise de variância, pois não foi possivel admitir a normalidade e homocedasticidade da variável número de lesões de cárie.

É bem verdade que Arbenz ${ }^{1}$ (1961) preferiu para dados percentuais a transformação arco-seno; todavia, em face do exposto por STEEL \& TORRIE ${ }^{23}$ (1960) para quando as percentagens estão com. preendidas entre zero e vinte, - situação que corresponde à de nossos dados decidimos adotar aquela transformação preconizada por êstes autores.

Teste de Tuckey - Quanto aos fatô. res para os quais foi observada diferen. ça estatisticamente significante, houve interêsse em verificar entre quais pares de 
VIEGAS, Ivette - Fluosilicato de zinco na prevensão de cárie dental em ratos. Rev. Saúde puibl., 1(1):79-91, jun. 1967.

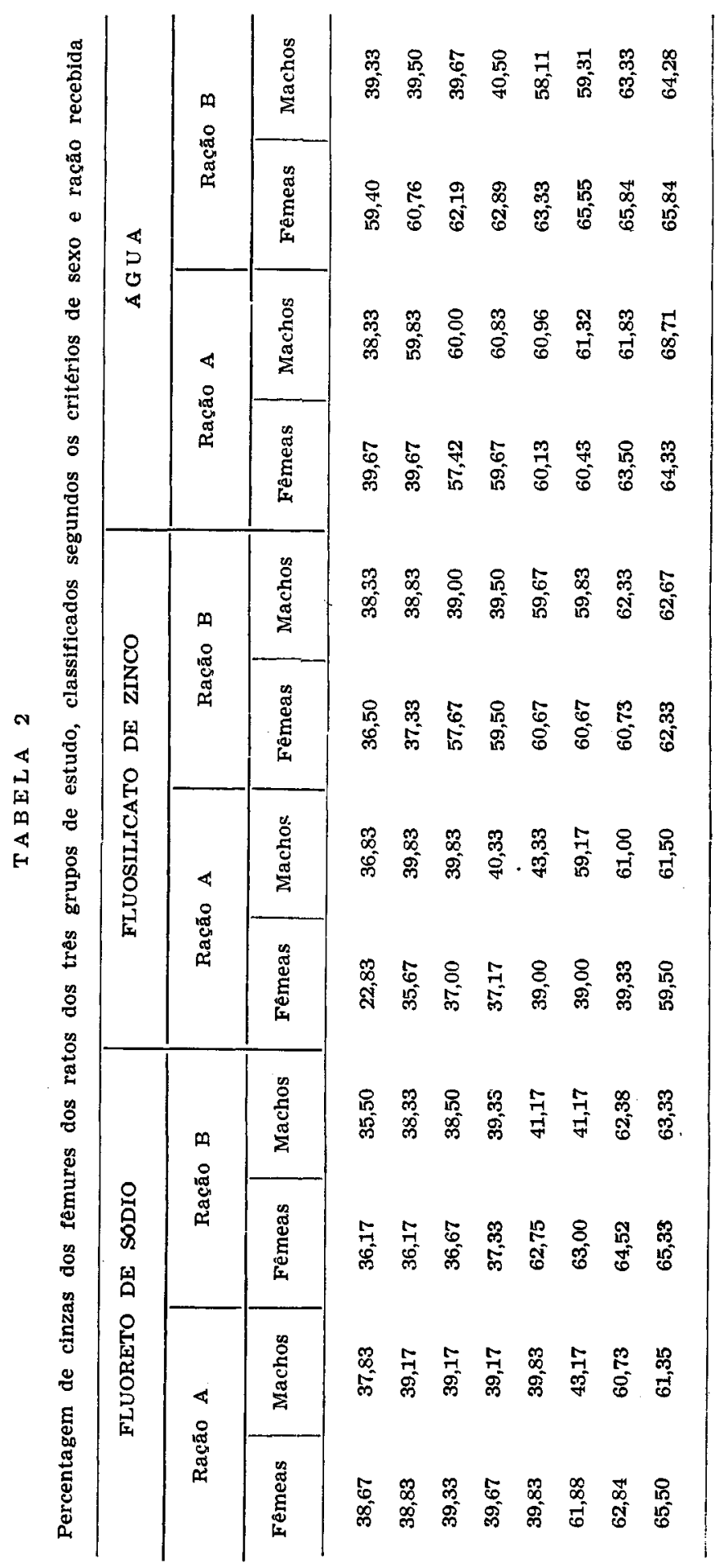


VIEGAS, Ivette - Fluosilicato de zinco na prevenção de cárie dental em ratos. Rev. Saúde puibl., 1(1):79-91, Jun. 1967.

grupos essa diferença não casual estava presente, daí termos utilizado o teste de Tuckey como referido por STEEL \& TORRIE ${ }^{23}$ (1960), o qual possibilita essa verificação.

\section{RESULTADOS}

Percentagem de cinzas nos fêmures Escolhemos os fêmures como osso padrão por ter em mente que Pourchet Campos ${ }^{19}$ (1953) já o recomendara como bem representativo do teor de flúor no restante do esqueleto.

As percentagens de cinzas nos fêmures de cada animal dos diferentes lotes compõem a Tabela 2.
A análise da variância, englobando os dados da Tabela 2, encontra-se resumida na Tabela 3 .

$\mathrm{O}$ fato de ter havido interação significante entre ração e sexo $(\mathrm{P}<5 \%)$ prejudicou o teste das possíveis diferenças devidas a raçōes e das possíveis diferenças devidas a sexos. No que concerne a soluçóes, a análise global mostrou significância para as diferenças observadas; entretanto, a aplicação do teste de Tuckey revelou que cada lote tratado, de per si, diferia do testemunha, mas que o lote tratado com o fluoreto de sódio não diferia significantemente do tratado com o fluosilicato de zinco.

TA B E L A 3

Análise de variancia da Tabela 2

\begin{tabular}{l|c|c|c|cc}
\hline \multicolumn{1}{c|}{ Fontes de Variação } & $\begin{array}{c}\text { Soma de } \\
\text { Quadrados }\end{array}$ & $\begin{array}{c}\text { Graus de } \\
\text { liberdade }\end{array}$ & $\begin{array}{c}\text { Quadrados } \\
\text { Médios }\end{array}$ & F & F 0,05 \\
\hline Entre Solucões & $1.990,67$ & 2 & 995,33 & 8,57 & $3,15^{* *}$ \\
Entre Raç̃es & 241,05 & 1 & 241,05 & - & - \\
Entre Sexos & 117,17 & 1 & 117,17 & - & - \\
Interação Solução/Ração & 417,28 & 2 & 208,64 & 1,79 & $3,15 * *$ \\
Interação Solução/Sexo & 246,59 & 2 & 123,29 & 1,06 & $3,15 * *$ \\
Interação Ração/sexo & 663,71 & 1 & 663,71 & 5,71 & $4,00 *$ \\
Interação Solução/Ração/Sexo & 224,03 & 2 & 112,01 & 0,96 & $3,15 * *$ \\
Residuo & $9.759,95$ & 84 & 116,19 & - & - \\
\hline Total & $13.660,45$ & 95 & 143,79 & - & - \\
\hline \multicolumn{1}{c}{ F 1,60 } & & & & &
\end{tabular}

Ficou assim demonstrado que os resíduos minerais eram menores nos fêmures dos animais tratados do que nos dos ani. mais testemunha.

Teor de flúor nas cinzas dos fêmures -_ Obtidos os resultados supra, passámos à determinação do teor de flúor nas cinzas advindas dos fêmures de cada animal.

Os resultados de tais determinações constituem a Tabela 4.

A análise de variância da Tabela 4, acha-se apresentada na Tabela 5 . 
VIEGAS, Ivette - Fluosilicato de zinco na prevenção de cárie dental em ratos. Rev. Saúde públ., 1(1):79-91, jun. 1967.

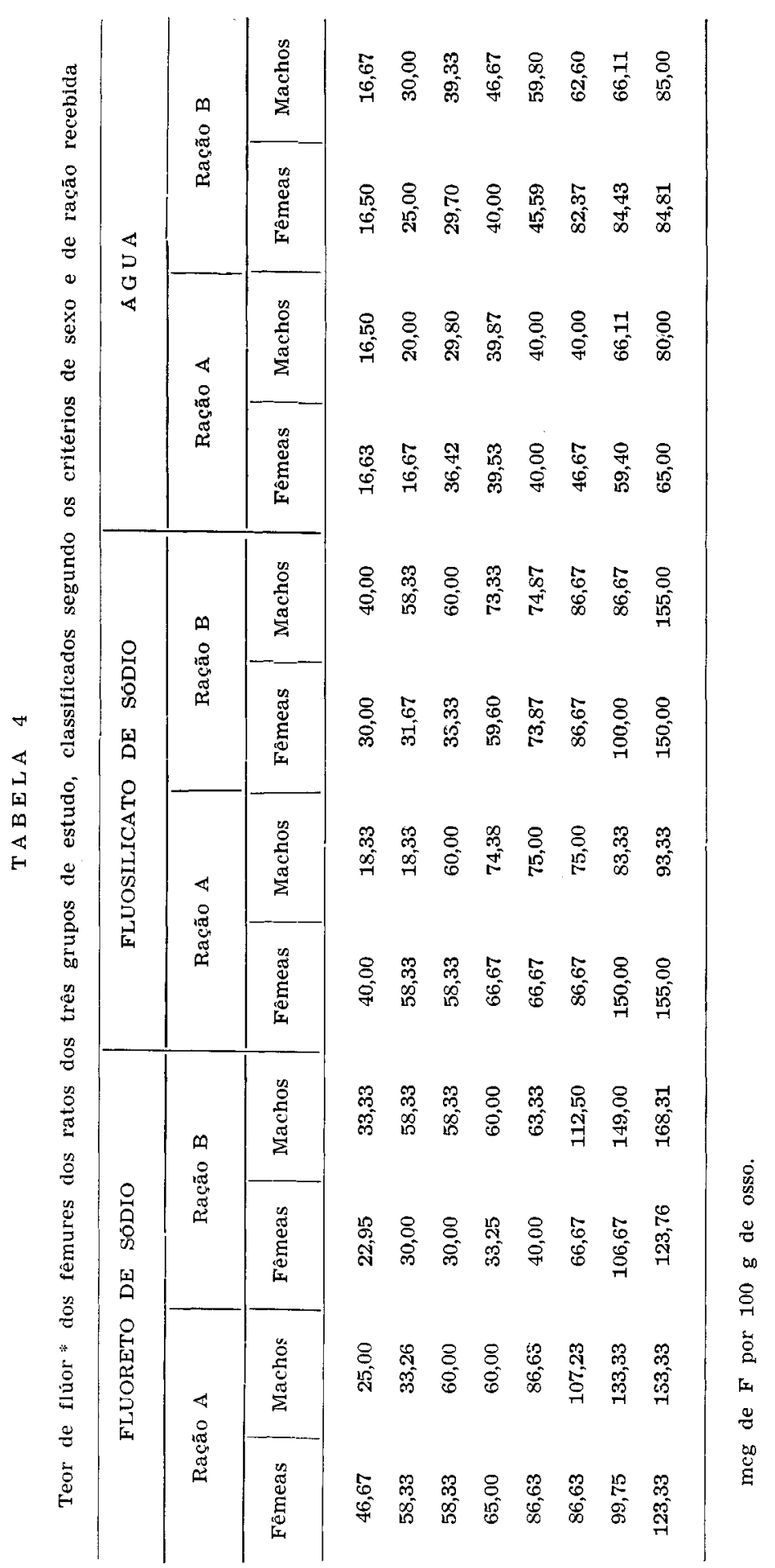


VIEGAS, Ivette - Fluosilicato de zinco na prevenção de cárie dental em ratos. Rev. Saúde públ., 1(1):79-91, jun. 1967.

TABELA 5

Análise de variância do conjunto dos dados da Tabela 4

\begin{tabular}{l|r|r|r|r|r}
\hline \multicolumn{1}{c|}{ Fontes de Variação } & $\begin{array}{r}\text { Soma de } \\
\text { Quadrados }\end{array}$ & $\begin{array}{c}\text { Graus de } \\
\text { liberdade }\end{array}$ & $\begin{array}{c}\text { Quadrados } \\
\text { Médios }\end{array}$ & F & F 0,05 \\
\hline Entre Soluções & $17.803,37$ & 2 & $8.901,68$ & 7,41 & $3,15 * *$ \\
Entre Rações & 33,71 & 1 & 33,71 & 0,03 & $4,00 *$ \\
Entre Sexos & 330,60 & 1 & 330,60 & 0,27 & $4,00 *$ \\
Interação Solução/Ração & $1.142,54$ & 2 & 571,27 & 0,47 & $3,15 * *$ \\
Interação Solução/Sexo & $2.135,68$ & 2 & $1.067,84$ & 0,89 & $3,15 * *$ \\
Interação Ração/sexo & $2.538,02$ & 1 & $2.538,02$ & 2,11 & $4,00 *$ \\
Interação Solução/Ração/Sexo & $1.520,87$ & 2 & 760,43 & 0,63 & $3,15 * *$ \\
Resíduo & $100.881,80$ & 84 & $1.200,97$ & - & - \\
\hline Total & $126.386,59$ & 95 & $1.330,38$ & - & - \\
\hline * F' 1,60 & F 2,60 & & & &
\end{tabular}

Vê-se que nenhuma interação significante houve entre os diferentes fatôres e que nenhuma diferença pôde ser atribuída à influência dos sexos ou das rações.

A análise global revelou, entretanto, diferenças significantes devidas aos tratamentos. Novamente aqui o teste de Tuckey revela que cada tratamento condicionou diferença significante com relação ao lote testemunha, mas que não houve diferença significante entre o lote tratado com o fluoreto de sódio e o com o fluosilicato de zinco.

Ficou assim comprovada maior concentração de flúor nas cinzas dos ossos dos animais tratados, quando comparados com os dos animais testemunha.

Lesões de cárie - Estabelecidas as percentagens de cinzas dos fêmures e sua riqueza em flúor, passámos à contagem das lesões de cárie, obtendo os resultados dispostos na Tabela 6, referentes, respectivamente, ao lote tratado com solução de fluoreto de sódio, ao tratado com solução de fluosilicato de zinco e ao lote testemunha.
0 conjunto dos dados da Tabela 6 (prèviamente transformados, como foi dito, segundo a expressão $\sqrt{x+\frac{1}{2}}$ ) foi submetido à análise de variância, a qual é apresentada na Tabela 7 .

A análise global não revelou qualquer interação de fatôres; tampouco mostrou diferença significante atribuível ao sexo. Foi demonstrada significância para diferenças atribuiveis às influências das soluções e às das rações.

$O$ teste de Tuckey esclareceu que as influências de ambas as soluções condicionaram diferenças significantes com relação ao lote testemunha, mas não reconheceu diferença entre as influências das soluções entre si.

Provas histológicas - Não constatamos no rim, fígado e glândula tireóide, pelas reações histológicas empregadas, alterações morfológicas em qualquer das peças estudadas. 
VIEGAS, Ivette - Fluosilicato de zínco na prevenção de cárie dental em ratos. Rev. Saúde pübl., 1(1):79-91, jun. 1967.

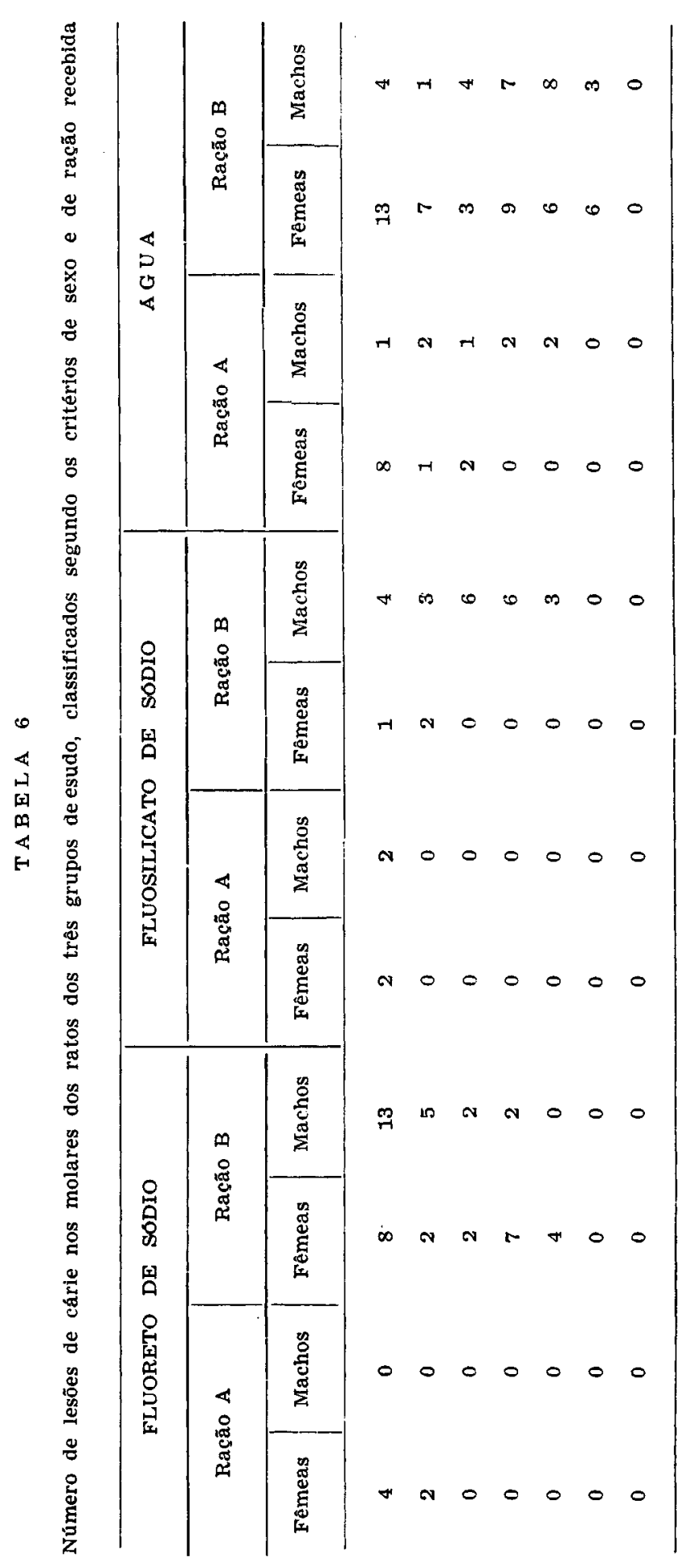


VIEGAS, Ivette - Fluosilicato de zinco na prevenção de cárie dental em ratos. Rev. Saúde públ., 1(1):79-91, jun. 1967.

T A B ELA 7

Análise de variáncia conjunta dos dados da Tabela 6, transformados segundo a expressão

$$
\sqrt{x+\frac{1}{2}}
$$

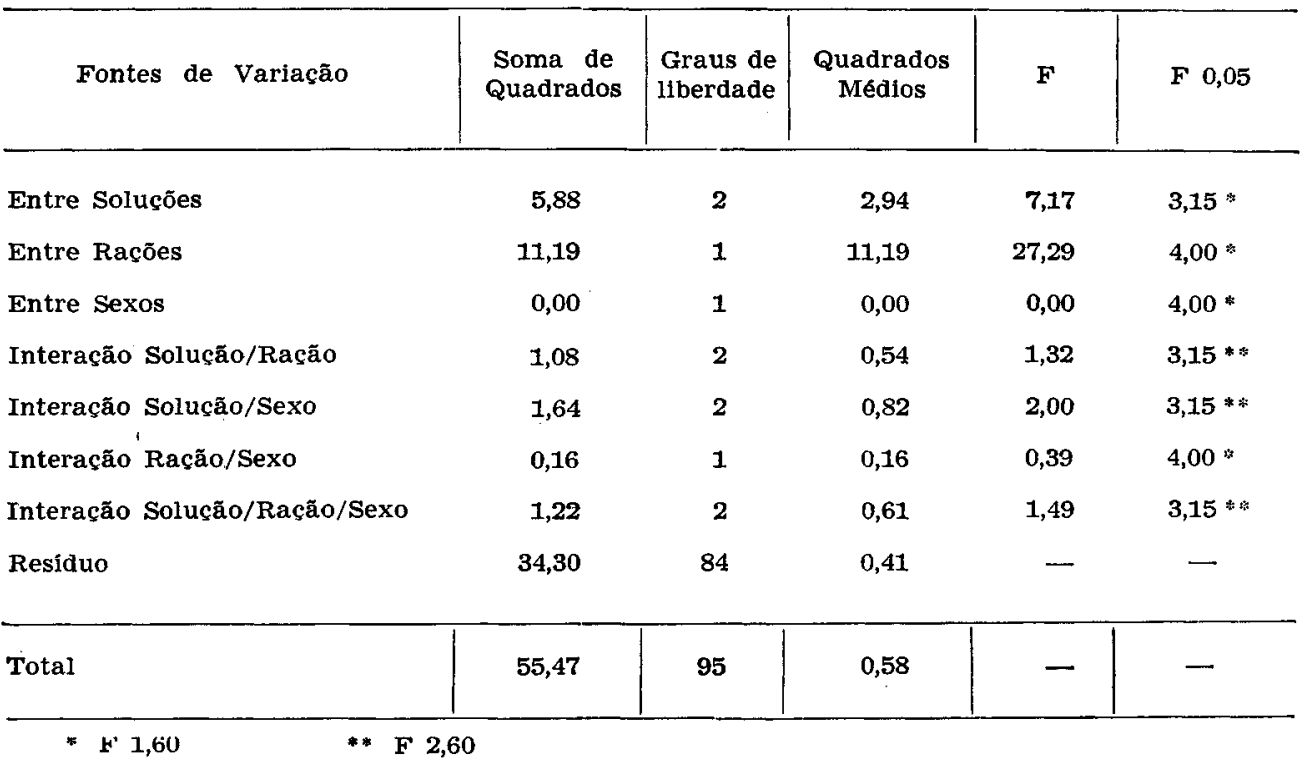

\section{DISCUSSAO DOS RESULTADOS}

$\mathrm{Na}$ análise dos resultados atinentes às cinzas dos fêmures, apenas os relativos às soluções fluoretadas condicionaram diferenças estatisticamente significantes. Todavia, pelo teste de Tuckey, observouse que não houve diferença entre os resultados da administração de solução de fluoreto de sódio e de fluosilicato de zinco mas, sim, entre os resultados da administração de cada uma delas e a água; em ambos os casos notou-se que nos animais tratados houve desmineralização.

Embora em menor proporção, tal fenômeno já tinha sido observado por McClune \& Mitchell ${ }^{16}$ (1931). Tais autores necessitaram, porém, para obter êsses resultados, usar concentraçöes de flúor cêrca de 60 vêzes superiores àquelas por nós utilizadas. Entretanto, é mister notar que ao receberem o halogênio, os ratos de suas experiências já estavam em pleno período de crescimento, ao passo que os nossos animais entraram em contato com o flúor ainda no útero materno, presumìvelmente desde a nidação do ôvo. $\mathrm{Na}$ diferença entre os dois delineamentos experimentais, talvez resida a explicação para o fato de termos obtido desmineralização com dose muito menor do que a considerada por McCluRe \& Mitchell ${ }^{14}$ (1954), como capaz de desencadear o fenômeno.

De qualquer modo, a desmineralização constatada implica na necessidade de novos e mais aprofundados estudos, a fim de ser melhor esclarecido êste aspecto do problema que permite perguntar: Será essa uma desmineralização específica para o rato? Ocorrerá também ela no homem?

LEONE et alii $^{12}$ (1955), ao examinarem radiològicamente a coluna lombar, 
VIEGAS, Ivette - Fluosilicato de zinco na prevenção de cárle dental em ratos. Rev. Saúde públ., 1(1):79-91, jun. 1967.

o sacro, a pelvis, os trocânteres e o têrço proximal do fêmur de uma população exposta a alto teor de flúor $(8 \mathrm{ppm})$, verificaram que apenas $15 \%$ de residentes permanentes mostraram ligeiras mudanças ósseas, muitas vêzes difíceis de serem reconhecidas. Essas mudanças não estavam associadas a outros sinais ou sintomas patológicos, exceto fluorose dental, e, segundo os autores, elas não eram devidas exclusivamente ao flúor.

McCauley \& McClure ${ }^{14}$

observaram o crescimento e desenvolvimento de crianças de 7 a 14 anos de idade que viviam em cidades cuja água apresentava de 3.5 a $6.2 \mathrm{ppm}$ de flúor. Pelo exame radiológico de ossos da mão e do pulso nenhum efeito adverso puderam constatar.

Ainda queremos assinalar os estudos que foram realizados por Stevenson \& Watson ${ }^{24}$ (1957), SCHLESINGER et alii ${ }^{20}$ (1956) e GeEver et alii ${ }^{9}$ (1958), os quais tampouco observaram efeitos sistêmicos do flúor sôbre o tecido ósseo.

Recentemente, Sognnaes ${ }^{22}$ (1965) relatou que se pode observar ação benéfica de flúor sôbre o tecido ósseo do homem, pelo emprêgo de doses diárias de 20 a 100 miligramas de flúor. Disse mais, que pesquisas nesse sentido têm sido encorajadoras, mas que muitos estudos adicionais se tornam necessários principalmente com referência aos sindromes ósseos.

Tudo tem indicado, até agora, que no ser humano o flúor não apresenta ação desmineralizadora. Mas é lícito interrogar: poderá ela ocorrer em populações portadoras de carências minerais? A interrogação permanece válida e cremos ser necessária essa verificação, não sòmente por critérios radiológicos, mas es. pecialmente pela análise quantitativa direta dos minerais nos ossos.

No exame das percentagens de cinzas de ossos vimos que, em nossa experiência, a análise revelou interação significante entre as influências dos fatôres sexo e ração, no sentido de que os valôres encontrados para as cinzas foram maiores para o sexo masculino nos animais que receberam a ração $A$ e, para o sexo feminino, nos que consumiram a ração $B$.

Nenhuma explicação encontramos para a interação observada; apenas podemos dizer que ela prejudicou a interpretação das possiveis diferenças condicionadas pelos fatôres sexo e ração.

$\mathrm{Na}$ análise dos dados relacionados a teor de flúor não ficou comprovada qualquer interação de fatôres. Tampouco foram significantes as diferenças porventura atribuíveis aos fatôres ração e sexo, ficando, entretanto, demonstrada significância para diferenças dependentes do efeito de soluções.

Aprofundando, pelo teste de Tuckey, a análise dêste tópico particular, verificámos que o efeito das duas soluções não diferiu entre si, mas que o de cada uma delas diferiu do observado no lote testemunha.

Realmente, isso era esperado pois, é fato deviadmente demonstrado, que existe correlação entre a ingestão de flúor e sua fixação no tecido ósseo; acontecimento similar ocorre com os tecidos dentais - esmalte e dentina.

O fato de não ter havido diferença estatisticamente significante entre os efeitos das soluções de fluoreto de sódio e fluosilicato de zinco sugere que tanto esta quanto aquela possibilitam fixação semelhante de flúor.

Zipkin \& McClure ${ }^{27}$ (1954) demons. traram que o fluoreto de sódio e o fluosilicato de amônio proporcionam deposição equivalente de flúor nos fêmures e, também nos dentes de ratos.

Ainda MCClure ${ }^{15}$ (1950) verificou que o fluoreto de sódio e o fluosilicato de sódio ensejam deposições similares de flúor nos fêmures, mandíbulas e dentes de ratos.

$\mathrm{Na}$ análise dos dados relacionados à cárie (les̃ão), não foi por nós observada interação entre os fatôres e também não foi encontrada diferença estatìsticamente significante, atribuível à influência do sexo. Esse resultado era previsto, pois é 
VIEGAS, Ivette - Fluosilicato de zinco na prevenção de cárie dental em ratos. Rev. Saúde públ., 1(1):79-91, jun, 1967.

fato aceito que a prevalência da cárie é semelhante nos dois sexos.

As diferenças atribuíveis a raçōes e a soluçōes foram estatìsticamente significantes. Estes achados estão de acôrdo com o esperado. Realmente, a ração $A$ fôra intencionalmente delineada para ser menos cariogênica que a $B$ que contém maior teor de glicides, entre êles razoável proporção de sacarose, ausente da ração $A$.

A análise confirmou que os ratos que receberam a ração $B$ tiveram maior número de lesões de cárie que os que receberam a ração $A$.

Por outro lado, os ratos que receberam as soluções de fluoreto de sódio e de fluosilicato de zinco tiveram significantemente menos cárie que os que receberam água, e isto pode ser atribuído à ação do flúor contido naquelas soluções, confirmando o que BarbérIo; GUIMAräes; Pourchet Campos ${ }^{4}$ (1963), entre outros, assinalaram: que existe "nítida relação entre a maior quantidade de flúor no fêmur e a menor ocorrência de cárie".

Novamente aqui o teste de Tuckey permitiu aprofundar a interpretação dos resultados, esclarecendo que os efeitos das soluções não diferiram estatìsticamente entre si, mas que o de cada uma delas diferiu do observado no lote testemunha. Isto equivale a dizer-se que não houve superioridade do fluosilicato de zinco sôbre o fluoreto de sódio no que diz respeito à proteção contra a cárie.

Entretanto, tendo em mente a observação de BRUDEVOLd et alii ${ }^{8}$ (1963) sôbre a concentração do zinco no esmalte e em face das médias de número de lesões encontradas nos animais de nossa experiência - 0,60 para o fluosilicato de zinco e 1,06 para o fluoreto de sódio - talvez se possa reconhecer uma tendência para número menor de cárie no lote tratado com o fluosilicato de zinco.

Se assim fôr considerado, novas investigações deverão ser iniciadas, a fim de se esclarecer se realmente existe ação sinérgica do zinco com o flúor para a proteção contra a cárie dental.

Em relação ao estudo histológico do rim, fígado e glândula tireóide, não pudemos verificar, como dissemos, qualquer alteração morfológica, quer nos lotes tratados, quer no testemunha.

Fato similar tem sido observado por autores como, por exemplo, TAYLOR ${ }^{26} \mathrm{e}$ OGILvie ${ }^{18}$. O primeiro, estudando ratos que receberam água com 50 ppm de flúor durante 6 meses, não encontrou no rim alterações estruturais. OGILviE ${ }^{18}$ produziu pequenas mudanças na tireóide de ratos, sòmente quando lhes aplicava intraperitonealmente $70-50 \mathrm{mg}$ de flúor em soluções isotônicas de cloreto de sódio.

Nosso trabalho confirma, pois, que o flúor não ocasiona alterações morfológicas nos órgãos estudados quando empregado na proporção de $1 \mathrm{ppm}$.

\section{CONCLUSOES}

Em vista do delineamento experimen. tal e à luz da análise, da discussão e da interpretação dos nossos resultados em confronto com os da literatura é lícito concluir :

$10^{\circ}$ - Os ratos que receberam o fluo. reto de sódio ou o fluosilicato de zinco adicionado à água de beber tiveram menor prevalência de cárie dental que aquêles que receberam água comum, não tendo havido diferença de comportamen. to entre os dois sais considerados.

2.0 - A prevalência da cárie dental entre os nossos animais de experiência foi semelhatne nos dois sexos.

$3 .^{\circ}$ - Houve maior prevalência de cárie dental nos ratos que receberam a ração $B$, relativamente aos que receberam a ração $A$.

4..$^{\circ}$ - 0 teor de flúor em cinzas de ossos de animais que receberam um ou outro dos sais de flúor ensaiados foi 
VIEGAS, Ivette - Fluosilicato de zinco na prevenção de cárie dental em ratos. Rev. saúde públ., 1(1):79-91, jun. 1967.

maior que nos de animais-testemunha, não tendo havido diferença entre os dois sais.

$5 .^{\circ}$ - Tanto a solução de fluoreto de sódio como a de fluosilicato de zinco condicionaram desmineralização óssea nos ratos, não tendo havido diferença entre as ações dos dois sais.

6. - Nas condições de nossa experiência não constatámos alterações morfológicas nos órgãos estudados (rim, fígado e glândula tireóide) .

\section{SU M M A R Y}

The purpose of this research performed in rats (Rattus norwegicus) was to observe if there is a synergic action of fluorine and zinc in order to obtain a greater reduction in dental caries. The study incolved three groups of rats receiving: $a$ ) zinc silicofluoride $1 \mathrm{ppm}, b)$ sodium fluoride - $1 \mathrm{ppm}$ and $c$ ) tap water. All groups included males and females, and were divided in sub-groups in accordance with cariogenic and non cariogenic diets. The data were treated by analysis of variance and the main conclusions obtained were the following: $1^{\text {st }}$ ) The group of zinc silicofluoride has shown less caries than the sodium fluoride group, but the difference was not statistically significant. When both groups $a$ and $b$ were compared to group $c$, the results were significant. $2^{\text {nd }}$ ) The rats receiving zinc silicofluoride or sodium fluoride have shown higher levels of fluorine in the bone ashes but the difference between them was not statistically significant. $3^{\text {rd }}$ ) The rats of both groups - zinc silicofluoride and sodium fluoride - have shown bone demineralizantion at equal level.

\section{A GRADECIMENTOS}

À Professôra Doutora M. A. Pourchet Campos, pela segura orientação que imprimiu ao nosso trabalho de pesquisa.
Ao Professor Doutor Guilherme Oswaldo Arbenz, pela motivação para que concretizássemos esta tese.

Ao Dr. Sergio M. Zucas e aos Instrutores Nelson Villa e Eymar Sampaio Lopes, pela assessoria proporcionada.

\section{REFERENCIAS BIBLIOGRAFICAS}

1. ARBENZ, O. G. - Contribuição para - estudo da estimativa da idade pelo numero de dentes permanentes irrompidos, em escolares da cidade de São Paulo, brancos, nascidos no Brasil... São Paulo, 1961, 121 p. (Tèse de Cátedra - Fac. Farm. Odon. USP). (Mimeografado).

2. ARNOLD Jr, F. A. et alii - Fifteenth year of Grand Rapids fluoridation study. J. Amer. dent. Ass., 65(6):780-785, Dec. 1962.

3. AST, D. B. \& FITZGERALD, B. - Effectiveness of water fluoridation. $J$. Amer. dent. Ass., 65(5):581-588, Nov. 1962.

4. BaRberio, J. C.; GUIMARAes Jr., P.; POURCHET CAMPOS, M. A. - Sal de cozinha, veículo para a administração do flúor. Rev. Fac. Farm. Bioqui. São Paulo, 1(2):125-134, jul./dez. 1963.

5. BLANEY, J. R. - A report on thirteen years of water fluoridation in Evanston, III. J. Amer. dent. Ass., 61(1): 76-79, July 1960.

6. BROWN, H. K. - The Brantford-Sarnia-Stratford fluoridation caries study 1961 report. Canad. J. Publ. Hlth, 53 (10):401-408, Oct. 1962 .

7. BRUDEVOLD, F.; STEADMAN, L. T.; SMITH, F. A. - Inorganic and organic components of tooth structure. Ann. New York Acad. Sc., 85:110-132, Nar. 1960

8. BRUDEVOLD, F. et alii - A study of zinc in human teeth. Arch. oral Biol., 8(2):135-144, Mar./Apr. 1963.

9. GEEVER, E. F. et alii - Pathological studies in man after prolonged ingestion of fluoride in drinking water. Publ. Hlth Rep., 73(8): 721-731, Aug. 1958.

10. HESS, W. C.; LEE, C. Y. - Isolation of chondroitin sulfuric acid from den- 
VIEGAS, Ivette - Fluosillicato de zínco na prevenção de cárie dental em ratos. Rev. Saúde públ., 1(1):79-91, jun. 1967.

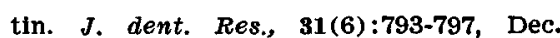
1952.

11. KEYES, P. H. - Dental caries in the molar teeth or rats. II. A method for diagnosing and scoring several types of lesions simultaneously. J. dent. Res., 37 (6):1088-1099, Nov./Dec. 1958

12. LEONE, N. C. et alii - A roentgenologic study of a human population exposed to high-fluoride domestic water. A ten-year study. Amer. J. Roentgenol., $74(5)$ : 874-885, Nov. 1955.

13. LOURES, O. F.; FREIRE, P. S. - A fluoretação da água de abastecimento de Baixo Guandu. Rev. mineira Odont. 3(2):52-62, mar./abr. 1962.

14. MCCAULEY, H. B.; McClURE, F. $\boldsymbol{J}$. - Effect of fluoride in drinking water on the osseous development of the hand wrist in children. Publ. Hith Rep., 69 (7) :671-783, July 1954.

15. MCCLURE, F. J. - Availability of fluorine in sodium fluoride vs. sodium fluosilicate. Publ. Hlth. Rep., 65(37):11751186, Sept. 1950.

16. MCCLURE, F. J.; MITCHELL, H. H. The effect on the calcium metabolism of albino rats and the composition of the bones. J. Biol. Chem., 90(1):297320, Jan. 1931.

17. MEGREGIAN, S. - Rapid spectrophotometric determination of fluorine with zirconium-erichrome cyanine R. Lake. Analyt. Chem., Easton, 26(7):1161-1166, July 1954.

18. OGILVIE, Apud HODGE, H. C.; SMITH, F. A. - Fluorine chemistry. New York, Academic Press, 1965. v. 4, p. 104.
19. POURCHET CAMPOS, M. A. - Contribuição para o estudo da fixação do fluior alimentar. São Paulo, 1953. 131 p. (Tese de Cátedra - Fac. Farm. Odon. USP.).

20. SCHLESINGER, E. R. et alii - Newburgh-Kingston caries-fluoride study. XIII. Pediatric findings after ten years. J. Amer. dent. Ass., 52(3):296-306, Mar. 1956.

21. SINGER, L.; ARMSTRONG, W. D. Determination of fluorine. Procedure based upon diffusion of hidrogen fluoride. Analyt. Chem., Easton, 26(5):904906, May 1954.

22. SOGNNAES, R. F. - Fluoride protection of bones and teeth. Science, 150 (3699) :989-993, Nov. 19, 1965.

23. STEEL, R. G. D.; TORRIE, J. H. Principles and procedures of statistics. New York, McGraw-Hill, 1960. p. 156158.

24. STEVENSON, C. A.; WATSON, A. R. - Fluoride osteosclerosis. Amer. J. Roentgenol., 78(1):13-18, July 1957.

25. TAMBURINI Jr., R.; ZUCAS, S. M. Determinação do flúor em material biológico. Rev. Fac. Farm. Bioquim. S. Paulo, 2(2):135-146, jul./dez. 1964.

26. TAYLOR, Apud SMITH, F. A. - Safety of water fluoridation. $J$, Amer. dent. Ass., 65(5):598-602, Nov. 1962.

27. ZIPKIN, I.; MCCLURE, F. J. - Cariosatic effect and metabolism of ammonium fluosilicate. Publ. Hlth Rep., $69(8)$ : 730-733, Aug. 1954. 